\title{
Application method of a coating technique to generate a water repellent effect on the fabric used for the manufacturing of the military clothing of the Colombian Army.
}

\author{
Andrés Mauricio Rojas González ${ }^{1}$, Manuela Pulgarín Sánchez ${ }^{2}$, Eliana Esmeralda Castañeda ${ }^{3}$ \\ "Researchteam of the Business MilitaryLogistics, Escuela de Logística del Ejército Nacional de Colombia \\ Calle 11 Sur \# 12 - 95 Este Av. Los cerros Bogotá D.C., Colombia \\ 1 andresrojasgonzalez@cedoc.edu.co \\ 2 manuelapulgarinsanchez@cedoc.edu.co \\ 3 elianacastanedapena@cedoc.edu.co
}

\begin{abstract}
The current article presents the results of the research paper called "Nano-engineered sprayed military uniforms". The project is put forward by the Escuela de Logística del Ejército Nacional de Colombia in agreement with EmpresaIndustrias W. Wilches S.A.S. The purpose of this study is to develop a waterproofing technique that could generate a water repellent effect on the military clothing of the National Army. Our Lab demonstrated that mixing chemical compounds with silicon dioxide Nano particles (SiO2) and applying several procedures to fabric samples (e.g. camouflage denim) it is possible to obtain the most efficient compound according to the contact angle theory. Subsequently, all the results were corroborated through water repellency laboratory testing by spraying it on the fabric - as the method of application. Spraying also allowed highlighting the significant improvement of the water repellent effect on the applied fabrics compared to the conventional fabrics.
\end{abstract}

Keywords: waterproof, Nano particle, Nano compound, water repellent, anti-absorption, polymer.

\section{INTRODUCTION}

As part of the optimization process and the continuous improvement of the military equipment that is provided to the active armed forces personnel, the National Army of Colombia is actively involved in the manufacture of the military camouflage clothing for exclusive and mandatory uses. In respect to this, the study of "Nano-engineered sprayed military uniforms" has been structured, consolidated and presented to the Dirección de Ciencia y Tecnología del Ejército Nacional de Colombia (DITEC). This project develops and implements the technique and the Nano particulated compound which, after being applied to the fabric, would place itself in the spaces between the fabric's microfibers, thus giving it the ability to rappel liquids; here, the efficiency of the different compounds and techniques that have been utilized is assessed.

First, preliminary laboratory testing was conducted to evaluate the efficiency of the compound. Second, followed the manufacture phase, where the military camouflaged clothing was actually fabricated by the Logistics Battalion $\mathrm{N}^{\circ} 1$ "Las Juanas". And third, the clothing samples were handed to soldiers, NCOs and officers of the National Army, who belonged to different operating units. These units were selected based on specific criteria and conditions of their stay in the field. In fact, special attention was dedicated to the climatic and geographical variables. Finally, this allowed the corroboration of the perception of the characteristics and the performance of this type of clothing. This specific protocol of field testing was performed for a 12-month time period.

Afterwards, the analysis of the results from the laboratory and the perception tests allowed establishing correlations between the satisfaction levels of the soldiers that wore the sprayed clothing and the ones that wore the not sprayed clothing. As a deduction, several observations regarding the application method of the coating technique were made, and the perception of the personnel and the performance of the fabric were qualitatively evaluated and categorized.

This research paper focuses on providing information to the National Army of Colombia and answering the following question: to what extent does the application of a coating that generates a water repellent effect in the clothing of the military impact the operating capacities and the wellbeing of the Colombian soldier? Moreover, it is taken into account that the military uniform is of mandatory use in the area of operations.

The creation of the chemical compound that gives the fabric the water repellent effect and the respective procedure of applying it to the fabric constitute themselves an important contribution to the future development of technologies that would improve the conditions of the material used by the National Army. 
The motivation and the morale of the armed forces personnel is directly related to the conditions of the work and tasks carried out by them. It was, thus, determined from the results that in the moment where the military personnel was using the covered clothing, the perception of their personal wellbeing and quality of life was improved, which resulted in a better performance of their appointed tasks

\section{Methodology}

Nanotechnology is the study and the development of systems at a nanometer scale. The scale applies the $10^{\wedge}-9$ factor to length units resulting in measurements of one billionth part of a meter $\left(10^{\wedge}-9\right.$ meters $)$. Such a precise measurement broadens the field of observation of new proprieties of materials as well as their many different phenomena [1].

The Nanoscience and Nanotechnology compose a set of studies, manufacturing processes and handling procedures of chemical, electronic, and other types of structures; also of devices and material systems at a nanometer scale. Therefore, the Nanoscience studies the phenomena and handles the matter at atomic, molecular and macromolecular scales, by the means of nanometer scales [2].

With the aim of establishing the degree of waterproofing of the fabrics it was deemed necessary to study the contact angle between the water drop and the fabric. On these grounds, the angle represents the degree of attraction between the molecules from the two surfaces when they come into contact. Afterwards, it was believed imperative to thoroughly explore other research studies surrounding the topic. Papers such as the ones who have used copper sulphate and silicone micro-emulsion for creating the water repellent effect [3], or for fabricating laminated fabric with recycled plastic[4], have highlighted the variety of compounds, processes and techniques which can be used for waterproofing a fabric. Thereupon, as a means of experimental validation the concept of Martínez et al. was adopted. Itstatesthefollowing:

If a drop of water is applied on a solid, smooth surface, and if the contact angle is less than $90^{\circ}$, the molecules of the liquid will tend to stick to the solid surface and hence the liquid dampens the surface. On the contrary, if the contact angle is higher than $90^{\circ}$, the molecules of the solid matter and the ones of the liquid tend to repel each other and hence the liquid doesn't dampen the surface [5, p. 211].

(a) $\alpha<90^{\circ}$ (el líquido "moja")

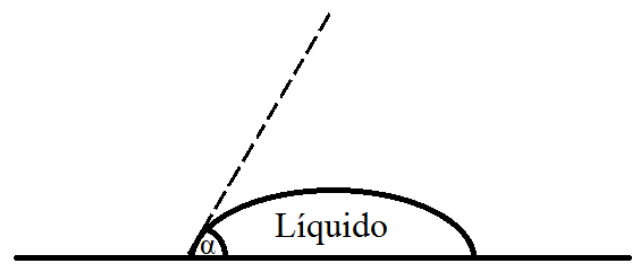

Sólido (b) $\alpha>90^{\circ}$ (el líquido "no moja")

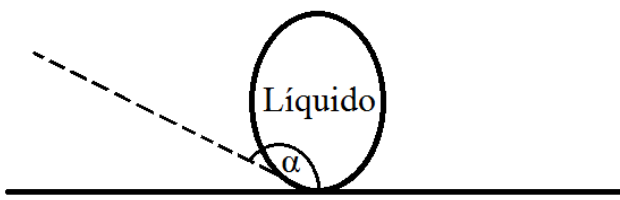

Sólido

Fig. 1. Contactangle. Liquid - Solid. Source: Martinez Alfaro, Martínez Santos, \& Castaño Castaño, 2006 [5]

The contact angle between a solid and a smooth surface and the liquid can determine if there is actual absorption of the liquid (see Fig. 1). This theory is based on the surface energy, thus the equilibrium contact angle can be calculated once the advancement and the recoil contact angles have been measured, on the condition that it is assumed that the surface is plane and smooth, as it was demonstrated by Tadmor [6] (see Fig. 2).

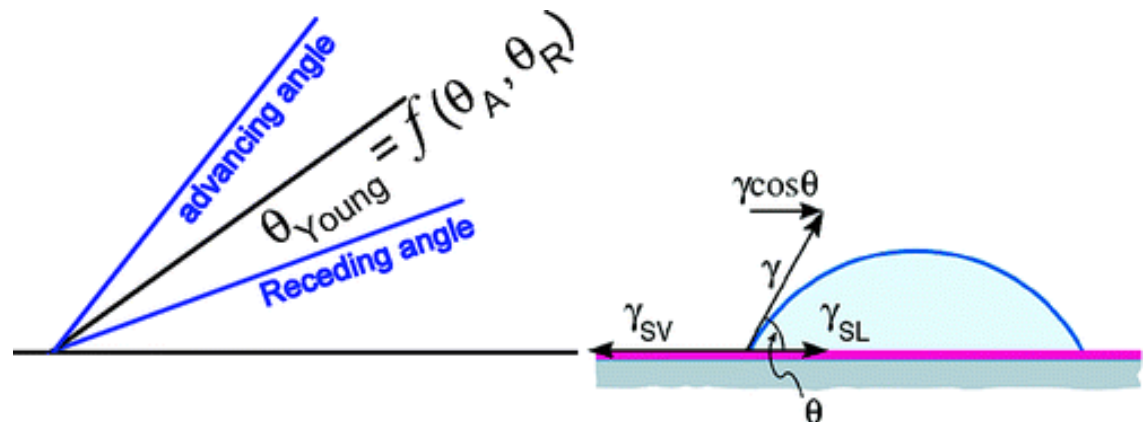

Fig 2. Presentation of the contact angle. Source: Tadmor. 2004 [6] 
Thereof, it can be deduced that the equilibrium contact angle is $\theta \mathrm{c}$ :

Where,

$$
\theta_{C}=\arccos \frac{r_{A} \cos \theta_{A}+r_{R} \cos \theta_{R}}{r_{A}+r_{R}}
$$

$$
r_{A}=\sqrt[3]{\frac{\sin ^{3} \theta_{A}}{2-3 \cos \theta_{A}+\cos ^{3} \theta_{A}}} r_{R}=\sqrt[3]{\frac{\sin ^{3} \theta_{R}}{2-3 \cos \theta_{R}+\cos ^{3} \theta_{R}}}
$$

That said, for methodological and experimental purposes three phases have been established:

\section{A. The elaboration of the application method of the compound.}

In this phase the compound and the appropriate application method were elaborated. This is to create the water repellent effect on the fabrics covered with a mixture of silicon dioxide particles (SiO2), with polymers and bonding agents. For the purpose of establishing an application method and ironing device was designed and created specifically for this end. The fabric is rolled up into the ironing device which then gradually extends into a spraying cycle with the pre-prepared compound at a rhythm of $45 \mathrm{ml} / \mathrm{m} 2$ and at a speed of $0,1 \mathrm{~m} / \mathrm{s}$. By doing so, the totality of the fabric was soaked and it was dried for 6 minutes at an average temperature of $170^{\circ} \mathrm{C}$ per every meter of fabric. Finally, the process culminated by visually inspecting the manipulated fabric and then packaging the fabric as to be delivered for later manufacturing.

B. Verificationbylaboratorytests.

Laboratory tests were performed to verify the effectiveness of the coating and its water repellent effect. Test “AATCC TM22-2017, Water repellency: Spraying test”, performed in 1941 by the Comite RA63 of AATCC (updated in 2017) [7], whose results established:

1) The purpose and scope of the test. Thistype of test is applicable to all type of textile material that has or not been applied a water repelling coating. It measures the water resistance of the fabrics. It is particularly useful to measure water repellency efficiency of the coatings applied to the fabrics.

2) The starting point. The water is sprayed against the surface which is stretched by a testing sample under controlled conditions. This creates a wet mark whose size depends on the relative water repellency of the fabric. The evaluation can thus be done by comparing the wet marks with images from a standard table.

Once the test has been established, five National Army pixel-patterned camouflage uniforms samples of clothing are manipulated in the laboratory. The 5 samples of clothing are: two jackets, two pairs of pants and a cap.

3) Testing process. The test was performed, as it is shown in table 1, for the two established conditions for the fabric with the applied technique as well as for the fabric that hasn't been submitted to any manipulation.

TABLE I. Test process AATCC 22.

\begin{tabular}{|c|c|c|}
\hline Test Substance & Test time & Elimination \\
\hline Water & Until the water has evaporated & Water was evaporated \\
\hline Dirt with water & 72 Hours & Dry cloth \\
\hline
\end{tabular}

\section{Analysis and Data Correlation.}

Data correlation could stablish if the already treated textile material (military camouflage denim) shows hydrophobic properties, based on [5], thus, corroborating the effectiveness of the compound through comparison of both treated and not treated textiles.

\section{RESULTS}

The results obtained from the laboratory testing applied to the pixeled fabric that was treated with the hydrophobic compound are shown here bellow.

Once the results of the AATCC TM22-2017 water repellency test are analyzed, the contact angles are measured under the request of the research team. The next table shows the contact angle of the elements applied to two textile samples: one was sprayed by the hydrophobic compound while the other remained unaltered. 
TABLE II. The contact angle during the testing

\begin{tabular}{|l|l|l|}
\hline Time (hours) & $\begin{array}{l}\text { Sprayedsimple } \\
\text { (contactangle in degrees) }\end{array}$ & $\begin{array}{l}\text { Notsprayedsimple } \\
\text { (contactangle in degrees) }\end{array}$ \\
\hline 0 & 120 & 63 \\
\hline 1 (72 hours) & 105 & 45 \\
\hline $2(84$ hours) & 75 & 23 \\
\hline
\end{tabular}

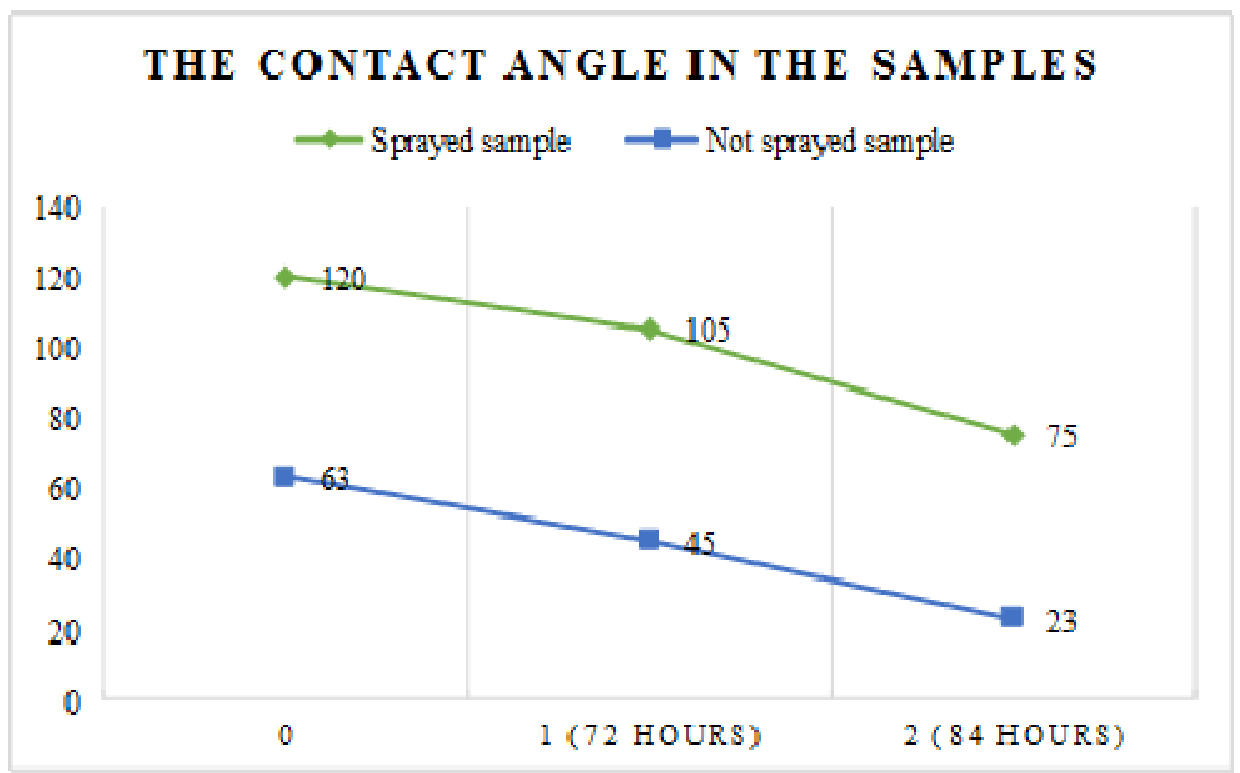

Fig. 3. Contact angle in the samples graph. Sources: Authors

A. Photographic Record test AATCC TM22

Beginning of the test, Time zero, $\mathrm{t}=0$

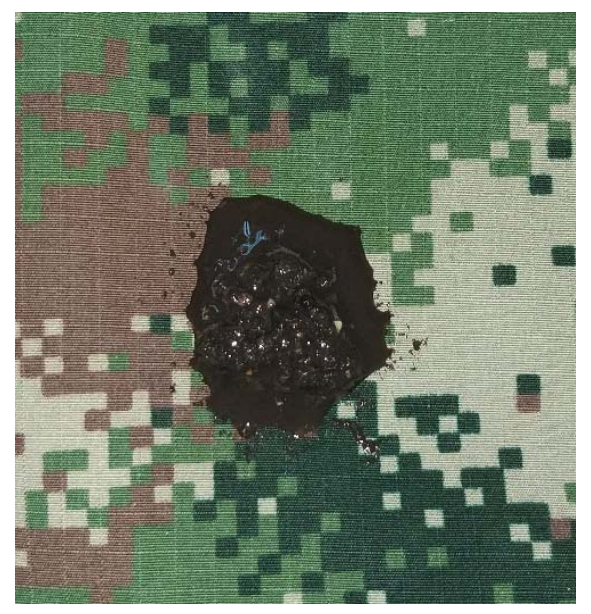

Fig.4. Not sprayed sample $\mathrm{T}=0$. Source: Authors

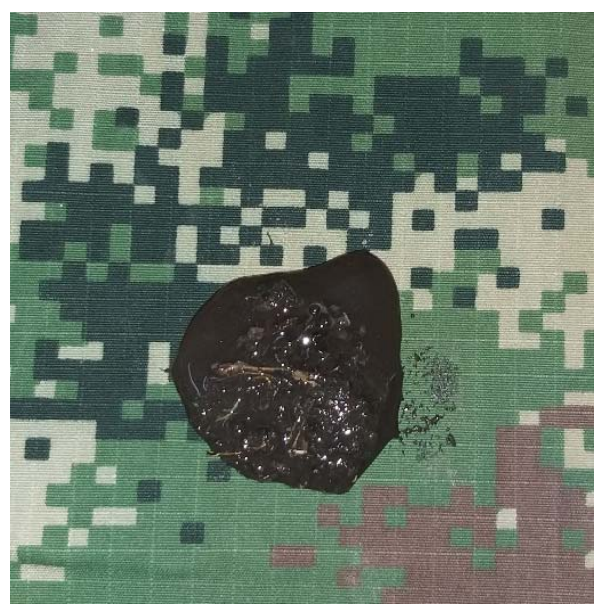

Fig.5. Sprayed sample $\mathrm{T}=0$. Source: Authors

After 72 Hours, time 1, $\mathrm{t}=1$ 


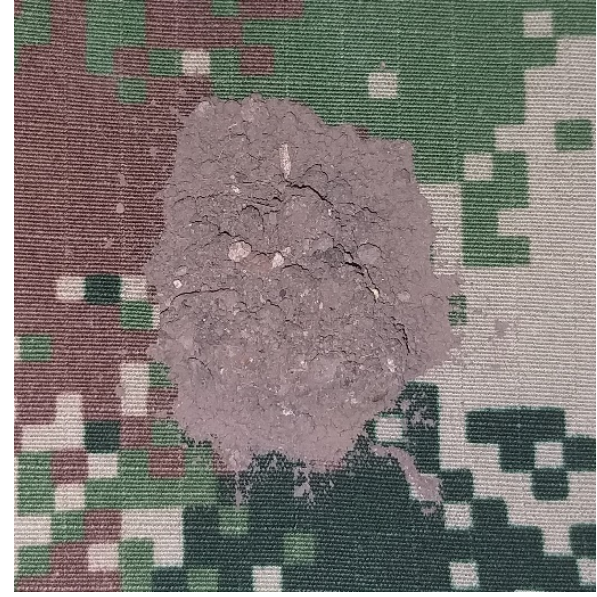

Fig.6. Not sprayed sample $\mathrm{T}=1$. Source: Authors

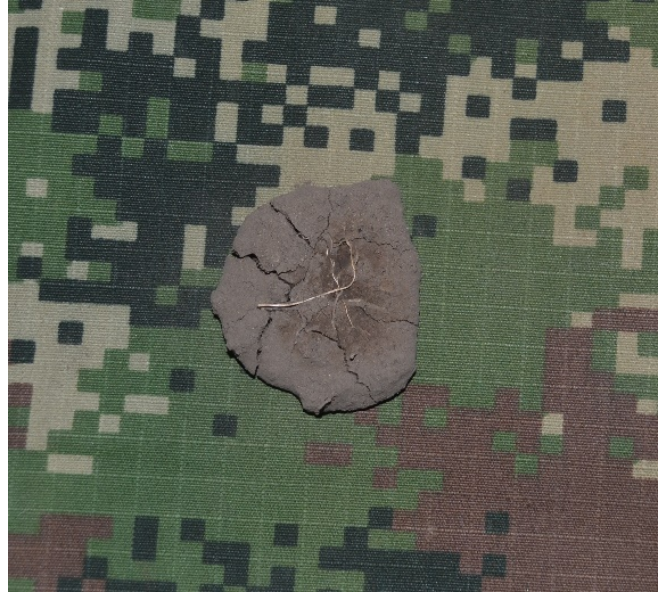

Fig.7. Sprayed sample $\mathrm{T}=1$. Source: Authors

After the cleaning process has been completed, time 2, $\mathrm{t}=2$

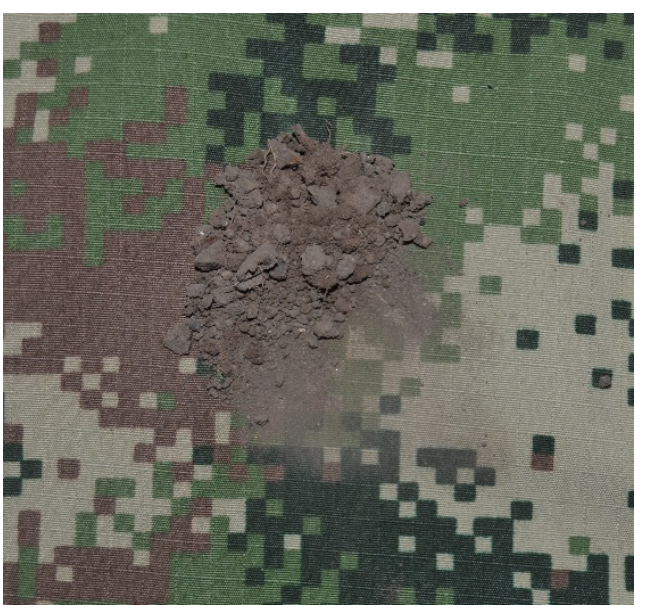

Fig. 8. Not sprayed sample T=2. Source: Authors

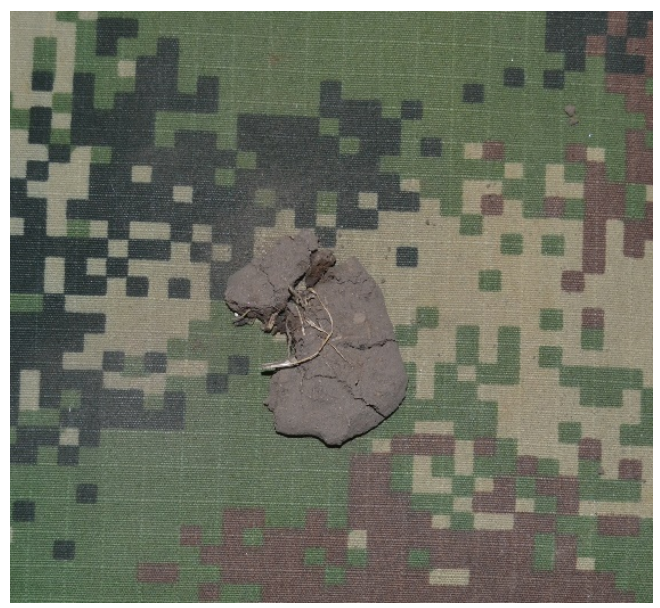

Fig.9. Sprayed sample T=2. Source: Authors

The final test report concludes that "after the cleaning process, the sprayed side allows to remove the dirt easily, while the not sprayed side of the sample does not permit completely removing the dirt". [8]

The coating is effective only if the application can be easily performed in order to favor the drying and adhesion of the compound to the fabric. The initial contact angle was within the pre-established range for the desired result; however its measure decreased according to the passing of time (see Fig. 3).

\section{CONCLUSION}

This project developed a compound and a technique to generate a water repellent effect on the denim fabric of the camouflaged military uniforms of the Colombian National Army. This has been done by applying the compound and drying it so to obtain the water repellent effect on the pixelled fabric of the military uniforms. The results of the laboratory testing highlighted that the technique is effective. This was established by using the contact angle theory as a frame of reference. Nevertheless, it is important to point out that the research could advance further improving the technique and testing its effectiveness on any type of fabric.

This research paper revealed many other distinctive traits produced by the application of the compound to the uniforms, which would be relevant to scientifically test and evaluate in the future. Such traits are the repellent effect of the vectors, the antibacterial propriety, the capacity of the fabric to allow the ventilation and the perspiration of the individual all while maintaining the water repellent effect, inter alia.

The development of the application method of the compound constitutes a baseline for the Colombian National Army to further develop technologies that optimize its technological, industrial and quality processes during the manufacturing of the fabric of the military uniforms.

\section{ACKNOWLEDGMENT}

To Industrias W. Wilches, for their support to the research, and their engagement with the innovation and the optimization of the processes for the improvement of the Colombian National Army capacities 


\section{REFERENCES}

[1] Poole, C. P., \& Owens, F. J. (2007). Introducción a la nanotecnología. Reverté.

[2] Martín-Gago, J. Á., Briones, C., Casero, E., \& Serena, P. A. (2014). El nanomundo en tus manos: Las claves de la nanociencia y nanotecnología. Barcelona: Planeta S.A.

[3] Alpala, Aza; Patricia, Alba. Aplicación de un acabado antibacteriano e impermeabilizante en la ropa de trabajo para los agricultores de San Gabriel utilizando sulfato de cobre y microemulsión de silicona. 2018. Tesis de Licenciatura.

[4] Velasco Miño, Betzabé. Eco-impermeabilización para textiles elaborados en fibras naturales. 2015. Tesis de Licenciatura. Pontificia Universidad Católica del Ecuador Sede Ambato.

[5] Martinez Alfaro, P. E., Martínez Santos, P., \& Castaño Castaño, S. (2006). Fundamentos de hidrogeología. Madrid: Ediciones MundiPrensa.

[6] Tadmor, R. (2004). Line energy and the relation between advancing, receding, and young contact angles. Langmuir, 20(18), 76597664.

[7] AATCC TM22-2017, Water Repellency: Spray Test. Developed in 1941 by AATCC Committee RA63 (revised 2017). [Online]. Available: https://members.aatcc.org/store/tm22/487/

[8] NanopoolGmH,“Report np surface protection”, Nanopool GmbH, Germany, Tech, Rep. 173/13, 28/03/2014.

\section{AUTHOR PROFILE}

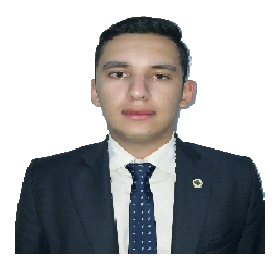

Andres Mauricio Rojas Gonzalez. Was born in Ibague, Tolima, Colombia, on April 12, 1991.Electronic engineer, National University of Colombia.Leader of the business military logistics research group and project coordinator in industrial and quality technology processes. Advisor and researcher of the School of Logistics of the National Army of Colombia.

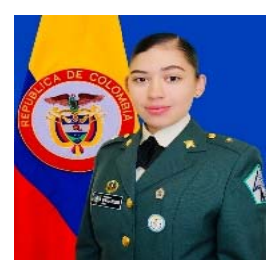

Manuela Pulgarín Sanchez (Born 08 April 1996). Military science professional, Officer of the Colombian Army. Specialist in Logistics Management. Head of the research department of the School of Logistics of the National Army of Colombia.

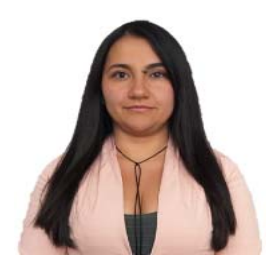

Eliana Esmeralda Castañeda Peña.Was born in Bogotá, Colombia.Industrial Engineer, Catholic University of Colombia. Specialist in Logistics Management and hospital administration. Student master's in management of value and logistics networks. Researcher of the School of Logistics of the National Army of Colombia. 